Rev. Latinoam. Psicopat. Fund., São Paulo, 17(4), 887-893, dez. 2014

http://dx.doi.org/10.1590/1415-4714.2014v17n4p887.6

\title{
Introdução ao texto clássico de James Sully*1
}

\author{
German E. Berrios*1
}

O texto clássico a seguir é importante por três razões: é de autoria de James Sully, um dos maiores filósofos-psicólogos britânicos do século XIX; apresenta uma interessante distinção entre os conceitos de ilusão e falácia; e oferece uma advertência velada sobre a eficiência epistemológica do método psicológico da introspecção. Cada um destes pontos serão brevemente tratados nesta introdução.

Palavras-chave: James Sully, ilusão, falácia, introspecção

*1 Tradução de Luana Villac.

${ }^{* 2}$ University of Cambridge (Cambridge, Grã-Bretanha) 


\section{James Sully (1842-1923)}

Importante filósofo-psicólogo da segunda metade do século XIX, James Sully possui uma obra que é interessante por combinar ideias inglesas e alemãs. Nascido em Somerset e destinado a dedicar-se aos negócios do pai e, então, à Igreja, Sully conseguiu em seu tempo livre estudar filosofia na Universidade de Londres e, em seguida, passou mais de um ano em Göttingen (Sully, 1918) assistindo a palestras de Lotze (Berrios, 2005) e Oswald. Ele voltaria à Alemanha anos mais tarde, desta vez para Berlim, a fim de trabalhar com Helmholtz e Dubois Raymond. Protegido de Alexander Bain, John Morley e Thomas Henry Huxley, Sully conseguiu entrar nos fechados círculos da intelectualidade londrina. Com inteligência, combinou seu interesse psicológico e filosófico com uma carreira jornalística que precisou seguir depois que a falência de seu pai o deixou sem seu subsídio mensal (Gurjeva, 2004).

Influenciado por Spencer e Darwin, Sully tornou-se um comprometido evolucionista e isso gradualmente levou-o a concentrar seu trabalho nas nascentes disciplinas da psicologia infantil e da pedagogia. Durante anos, tentou obter uma posição em alguma universidade inglesa e creditava seu insucesso ao fato de não ter recebido uma educação em Cambridge ou Oxford. Finalmente, em 1892, foi eleito para a Cátedra Grote de Filosofia da Mente e Lógica na University College, em Londres. Aposentou-se em 1903.

Sully escreveu artigos sobre uma variedade de temas e se destacou em fazer deles livros, tanto na forma de monografias como na de manuais didáticos. Suas obras Outlines of Psychology (1884; nova edição, 1892),

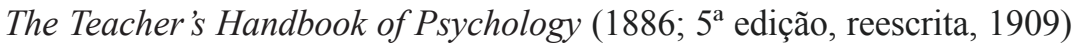
e The Human Mind (1892) seriam utilizadas em universidades britânicas e norte-americanas e algumas foram traduzidas para o francês e alemão. Sua monografia intitulada Illusions: A Psychological Study (1891), uma versão expandida do texto a seguir, deve ser considerada um dos melhores livros ingleses do século XIX sobre o assunto. 


\section{CLÁSSICOS DA PSICOPATOLOGIA}

Ideologicamente, Sully era um pensador teórico que concebia a psicologia como uma disciplina essencialmente dedicada à conceituação da mente. Ele próprio tinha pouco interesse na pesquisa empírica, mas ainda assim incentivou a criação de um Laboratório de Psicologia na Universidade de Londres. Como evidenciado no texto clássico que se segue, Sully acreditava na introspecção, mas estava ciente de suas dificuldades epistemológicas. Morreu em 1923, e por razões pouco claras seu nome rapidamente caiu em declínio nos anais históricos da Psicologia Europeia (Gurjeva, 2002). Não há dúvida, entretanto, que ele tinha um domínio original de seu tema, que foi capaz de buscar inspiração nas ideias alemãs e que desde muito cedo entendeu que a Fisiologia da Mente, no sentido que lhe fora ensinado por Helmholtz e Dubois Reymond durante sua segunda temporada alemã, era essencial para o desenvolvimento da psicologia (Sully, 1876).

\section{Ilusão versus Falácia}

Em meados do século XIX, o conceito de "falácia" ainda tinha uma definição restrita. Era usado tanto para paralogismos (isto é, falsos silogismos de cuja falsidade o usuário não tinha conhecimento) quanto para sofismas (isto é, argumentos ilusórios usados deliberadamente para enganar). Falácias eram, assim, consideradas características lógicas de uma afirmação (Hamilton, 1874, p. 449; Woods, 2007).

Até então, o significado predominante de "Ilusão" também havia sido cognitivo: "O fato ou a condição de ser enganado ou iludido pelas aparências, ou um exemplo disso; um estado mental que envolve a atribuição de realidade ao que é irreal; uma concepção ou ideia falsa; um engano, ilusão, fantasia..." (OED, 2009) e, portanto, tendia a sobrepor-se ao significado de falácia. Com efeito, ilusões eram consideradas falácias lógicas com alguma frequência. No entanto, no início do século XIX, o termo ilusão iniciou uma nova carreira, desta vez dentro da nova linguagem da psicopatologia, como companheira do termo alucinação (Esquirol, 1838): a alucinação era então definida como uma "percepção sem objeto" e a ilusão como "uma percepção distorcida". Com isso, tornou-se importante diferenciar ilusão de falácia; caso contrário, o significado lógico persistente de ilusão (como falácia) poderia contaminar seu significado psicopatológico.

Sully percebeu a confusão e dedicou-se a esclarecê-la. Em primeiro lugar, ofereceu uma tipologia das ilusões: "1) de percepção externa; 2) de introspecção ou percepção interna; 3) de memória; e 4) de crença". (Sully, 1881, p. 2). Isso foi desenvolvido por ele mais detalhadamente dez anos depois (Sully, 1891). Em seguida, propôs-se a diferenciar Ilusão de Falácia: 
Finalmente, devemos observar que nossa definição de ilusão de introspecção serve para distingui-la da falácia da introspecção pela ausência de qualquer coisa similar a um processo consciente de inferência. Assim, se considerarmos errônea a derivação de Descartes do fato da existência de Deus de sua posse da ideia, tal ação de raciocínio conscientemente realizada constituiria antes uma falácia do que uma ilusão de introspecção. (Sully, 1881, pp. 3-4)

Sully introduziu, assim, "intencionalidade" e "consciência" como critérios de distinção e, desta forma, libertou a ilusão (pelo menos dentro da psicologia e da psicopatologia) de sua definição lógica comum.

\section{O conceito de Introspecção}

No momento em que Sully escreveu seu artigo, a Introspecção ainda era aceita como um inconteste método de pesquisa dentro da psicologia. Ele a descreveu como uma "percepção interior", no que simplesmente traduziu para o inglês a velha noção de innere Wahrnehmung que aprendera com seus professores alemães (Boring, 1953). No entanto, nem todo mundo na Alemanha estava feliz com esta definição. Wundt, por exemplo, já havia visto o perigo epistemológico de definir a introspecção como "percepção" (pois isso rapidamente levava a uma regressão infinita) e preferiu defini-la como Selbstbeobachtung, ou seja, como "auto-observação".

Esta distinção claramente operou uma separação no conceito de introspecção conforme entretido pelas escolas inglesa e alemã. Assim, enquanto Mills, James e Titchener (Wilson, 1991; Beenfeldt, 2013) defendiam a opinião de que esta era apenas uma forma de percepção interna, Müller, Wundt, Lipps e Külpe a viam como uma forma de observação (Desfranzir, 1980).

Escrever sobre as ilusões de introspecção colocou um dilema para Sully: por um lado, defendia que a "percepção interior" afetada pelas ilusões poderia fatalmente minar o valor e a utilidade da introspecção; por outro, acreditava na introspecção e não queria atacar o principal método de investigação da psicologia. Isso explica seu tom delicado e quase apologético:

Ao delinear esse esboço bruto das Ilusões de Introspecção eu não tinha nenhum objeto prático em vista. Tentei olhar todos os fatos à parte de quaisquer conclusões a serem tiradas deles. A questão de o quanto a possibilidade de erro em qualquer região de investigação invalida todo o processo é difícil; e a questão sobre se as ilusões às quais estamos sujeitos na introspecção afetam materialmente o valor do método introspectivo na psicologia, como afirmam muitos, é sutil demais para ser tratada agora. (Sully, 1881, p. 17; grifo meu) 


\section{CLÁSSICOS DA PSICOPATOLOGIA}

No entanto, seu olhar aguçado já havia notado as fraturas internas na noção de introspecção que os filósofos posteriores viriam a explorar e que no caso levou ao fim de um dos mais importantes métodos da psicologia (Dodge, 1912; Lyons, 1986). O fato, porém, de a introspecção ter sobrevivido na psicopatologia mostra o quanto ela é importante como fonte de informações sobre as experiências subjetivas anormais. Repetidamente, mesmo nos casos de psicose grave, espera-se que o paciente seja um repórter objetivo de sua própria sintomatologia. Isto sugere que o conceito de introspecção necessita de um tratamento e justificação diferentes a este respeito. É surpreendente que este trabalho ainda não tenha começado a sério.

\section{Referências}

Beenfeldt, C. (2013). The Philosophical Background and Scientific Legacy of E. B. Titchener's Psychology: Understanding Introspectionism. Berlin: Springer.

Berrios, G.E. (2005). Lotze and his 'Medicinische Psychologie oder Physiologie der Seele'. History of Psychiatry, 16, 117-127.

Boring, E. (1953). A History of Introspection. Psychological Bulletin, 50, 169-189.

Danziger, K. (1980). The History of Introspection reconsidered. Journal of the History of the Behavioral Sciences, 16, 241-262.

Dodge, R. (1912). The limits of introspection. American Journal of Psychology, 23, 214-229.

Esquirol, E. (1838). Des Maladies Mentales (Vol. 1). Paris: Baillière.

Gurjeva, L.J. (2002). Sully, James (1842-1923). In W.J. Mander \& A. Sell (Eds). The Dictionary of Nineteenth-Century British Philosophers (Vol. 2, pp. 1088-1093). Bristol: Thoemmes Press.

Gurjeva, L.J. (2004). 'Sully, James (1842-1923). In Oxford Dictionary of National Biography. Oxford: Oxford University Press.

Hamilton, W. (1874). Lectures on Metaphysics and Logic (Vol. 3). Edinburgh: William Blackwood and Sons.

Lyons, W.E. (1986). The Disappearance of Introspection. Cambridge: MIT Press.

OED (2009). Oxford English Dictionary ( $2^{\text {nd }}$ Ed.). Oxford: Oxford University Press.

Sully, J. (1818). My Life and Friends. A Psychologist's Memories. London: T Fisher.

Sully, J. (1876). Physiological Psychology in Germany. Mind, 1, 2-43.

Sully, J. (1881). The Illusions of Introspection. Mind, 6, 1-18.

Sully, J. (1891). Illusions: a Psychological Study. New York: Appleton.

Wilson, F. (1991). Mill and Comte on the Method of Introspection. Journal of the History of the Behavioral Sciences, 27, 107-129.

Woods, J. (2007). The Concept of Fallacy is Empty. In L. Magnani (ed.). Model-Based Reasoning in Science, Technology, and Medicine (pp. 69-90). Berlin: Springer. 


\section{Resumos}

(Introduction to James Sully's classical text)

The classical text reproduced below is important for three reasons: it was written by James Sully, one of Britain's most outstanding 19th-century philosophers and psychologists; it makes an interesting distinction between the concepts of illusion and fallacy; and it contains a veiled warning as to the efficiency of the epistemological method of psychological introspection. Each of these points is dealt with briefly in this introduction.

Key words: James Sully, illusion, fallacy, introspection

(Introduction au texte classique de James Sully)

Le texte classique qui suit est important pour trois raisons: il a été écrit par James Sully, l'un des plus grands philosophes-psychologues britanniques du XIXe siècle, il présente une distinction intéressante entre le concept de l'illusion et celui du leurre et fournit un avertissement voilé sur l'efficacité épistémologique de la méthode psychologique de l'introspection. Chacun de ces points sera traitée brièvement dans cette introduction.

Mots clés: James Sully, illusion, leurre, introspection

(Introducción al texto clásico de James Sully)

El siguiente texto clásico es importante por tres razones: es de la autoria de James Sully, uno de los mayores filósofo y sicólogo británico del siglo XIX; presentauna distinción interesante entre los conceptos de ilusión y falácia; y ofrece una advertencia velada sobre la eficiencia epistemológica del método psicológico de la introspección . Cada uno de estos puntos seráqn brevemente tratados en esta introducción.

Palabras clave: James Sully, ilusión, falácia, introspección

(Einleitung in den klassischen Text von James Sully)

Der im Anschluss dargestellte klassische Text ist aus drei Gründen von großer Bedeutung: er stammt von James Sully, einem der bedeutsamsten britischen Philosophen und Psychologen des 19. Jahrhunderts. Er zeigt einen interessanten Unterschied zwischen den Konzepten der Illusion und dem Schwindel auf und, drittens, stellt er eine unterschwellige Ermahnung bezüglich der epistemiologischen Effizienz der psychologischen Methode der Introspektion. In dieser Einleitung werden diese drei Aspekte kurz beleuchtet.

Schlüsselwörter: James Sully, Illusion, Schwindel, Introspektion 


\section{CLÁSSICOS DA PSICOPATOLOGIA}

Citação/Citation: Berrios, G.E. (2014, dezembro). Introdução ao Texto Clássico de James Sully. Revista Latinoamericana de Psicopatologia Fundamental, 17(4), 887-893.

Editor do artigo/Editor: Prof. Dr. German E. Berrios

Recebido/Received: 13.8.2014/ 8.13.2014 Aceito/Accepted: 30.10 .2014 / 10.30.2014

Copyright: (C) 2009 Associação Universitária de Pesquisa em Psicopatologia Fundamental/ University Association for Research in Fundamental Psychopathology. Este é um artigo de livre acesso, que permite uso irrestrito, distribuição e reprodução em qualquer meio, desde que o autor e a fonte sejam citados / This is an open-access article, which permits unrestricted use, distribution, and reproduction in any medium, provided the original authors and sources are credited.

Financiamento/Funding: O autor declara não ter sido financiado ou apoiado/ The author has no support or funding to report.

Conflito de interesses/Conflict of interest: $\mathrm{O}$ autor declara que não há conflito de interesses / The author has no conflict of interest to declare.

\section{German E. Berrios}

Médico e filósofo pela Universidad Nacional de San Marcos, Lima, Peru; Psiquiatra; Neurologista; Psicólogo; Filósofo; Historiador e Filósofo da ciência (Oxford University, England); Professor de Neuropsiquiatria e de Epistemologia da Psiquiatria (University of Cambridge, England), desde 1976; Neuropsiquiatra e Chefe do Departamento de Neuropsiquiatria do Hospital Addenbrooke, University of Cambridge, por 32 anos; Coordenador do Comitê de Ética em Pesquisa com Humanos na mesma universidade, por vinte anos; Editor Responsável de History of Psychiatry; Autor de 14 livros, incluindo The History of Mental Symptoms, Descriptive Psychopathology since 19th Century (Prêmio Nacional BMA, 1997), A History of Clinical Psychiatry (com Roy Porter), e Delirio (com F. Fuentenebro) e mais de 400 artigos e capítulos de livros; Membro do Royal College of Psychiatrists; da Associação Britânica de Psicologia e da Academia Britânica de Ciências Médicas; Membro Vitalício do Robinson College, Cambridge; doutor Honoris Causa da Universidade de Heidelberg (Alemanha), da Universidade Nacional Mayor de San Marcos (Peru) e da Universidad Autónoma de Barcelona (Espanha); Grão Oficial da Ordem del Sol (Condecoração do Governo Peruano, 2007); prêmio Ramon y Cajal 2008 concedido pela Asociación Internacional de Neuropsiquiatria.

University of Cambridge

Box 189, Hills Road

Cambridge,

UK CB2 2QQ 